\title{
Estimating Probability of Instability of Haulage Drift with Respect to Mining Sequences
}

\author{
Wael Abdellah ${ }^{1}$, Hani S. Mitri ${ }^{1}$, Denis Thibodeau ${ }^{2}$ and Lindsay Moreau-Verlaan ${ }^{2}$ \\ 1. Department of Mining and Materials Engineering, Faculty of Engineering, McGill University, Quebec H3A OE8, Canada \\ 2. Vale Ltd., Ontario POM 1NO, Canada
}

\begin{abstract}
Haulage drifts play a vital role in providing personnel and equipment access to ore extraction areas for mine production. Thus, their stability is of crucial importance during the life of a mine plan. Many Canadian mines use longhole mining methods or one of its variants. These methods require access to the orebody through haulage drifts on multiple levels. This paper examines the stability of mine haulage drifts with respect to planned mining sequence. A case study of an underground mine is presented. The case study examines \#1 Shear East of the Garson Mine in Sudbury, Ontario. A two-dimensional, elastoplastic, finite difference model (FLAC 2D) is developed for a haulage drift situated $1.5 \mathrm{~km}$ below surface in the footwall of the orebody. The stability of the haulage drift is evaluated in terms of the spread of yield zones into the rockmass due to nearby mining activities. The performance of the drift stability is evaluated at various mining stages, employing the RMC (Random Monte-Carlo) technique in conjunction with finite difference modeling to study the probability of unsatisfactory performance of the drift. The results are presented and categorized with respect to probability, instability and mining stage.
\end{abstract}

Key words: Haulage drifts stability, numerical modeling, RMC, yielding zone.

\section{Introduction}

Haulage drifts are the only access where loaders and/or trucks travel through, hence their stability and functionality are crucial to the success of a mining operation. They must remain stable during their entire service life. The stability of haulage drifts may be influenced by many factors such as the strength and quality of the rockmass, mining depth and distance between haulage drifts and the stopes and more importantly nearby mining activity [1]. As mines continue to reach deeper deposits, haulage drifts are expected to experience higher pre-mining stress conditions, thus suffering from more stability problems.

Different stope extraction sequences will result in different mining-induced stresses, which in turn, will have varying influence on the drift stability condition.

Corresponding author: Wael Abdellah, Ph.D. student, research fields: rock mechanics, geomechanics and geotechnical risk assessment. E-mail: wael.abdellah@mail.mcgill.ca.
An evaluation of this interaction from a probabilistic perspective will be the focus of this paper.

\subsection{Garson Mine Geology}

The Garson nickel-copper (Ni-Cu sulphides) mine is located in Greater Sudbury, Ontario. It comprises two orebodies namely \#1 Shear and \#4 Shear that runs 250 feet to the north of \#1 Shear. The two orebodies have a strike length of about 2,000 feet, dip about 70 degrees to south and vary in size and shape. An Olivine Diabase Dyke crosses these two orebodies near the mid-span on the 5,100 level. The dyke is steeply dipping to south-west and continues with depth. The footwall typically consists of GS (greenstone) and the hanging wall consists of MTSD (metasediments). The mine has essentially been in operation for 100 years and has produced 57.2 million tons containing an average grade of $1.33 \%$ copper and $1.62 \%$ nickel [2].

\subsection{Case Study and Problem Definition}

A typical section is taken in the \#1 Shear 
East-Orebody, as shown in Fig. 1, of Garson Mine of Vale, Sudbury, Ontario. The study zone is divided into three areas: HW (hanging wall), orebody and FW (footwall). The orebody consists of MASU (massive sulphide) rock. The hanging wall contains MTSD and the footwall comprises of GS rock. The haulage drift is driven in the footwall parallel to the orebody for the length of its strike (approximately $200 \mathrm{~m}$ long) with cross section dimensions of $5 \mathrm{~m}$ by $5 \mathrm{~m}$ with a slightly arched roof. The drift primary support system includes $1.8 \mathrm{~m}$ (6 ft.) long tendons in the haulage drift sidewalls and $2.4 \mathrm{~m}$ (8 ft.) long tendons in the drift back, Grade 60, $19 \mathrm{~mm}$ diameter (3/4 inches) resin grouted rebars.

Rockmass properties and backfill mechanical properties are obtained from a study conducted by Golder Associate and MIRARCO [3] and are listed in Tables 1 and 2, respectively.

\section{Probabilistic Methods}

Due to the heterogeneity of the rockmass, data from underground excavations are limited. Therefore, a great deal of uncertainty is inherent in the design of underground excavations. In order to develop a reliable design approach, one must use methods that incorporate the statistical variation of the numerical model input parameters representing the rockmass properties, i.e., mean, variance and standard deviation, as well as the design of rock failure criteria [4].

One of the most popular stochastic methods, which is used in this study, is the RMC (Random Monte-Carlo) technique. In this method, material properties vary spatially within the same region, for example, varying the cohesion and friction angle properties spatially within the footwall by randomly assigning values from a defined distribution to zones within the region [5].

\section{Drift Instability Criterion}

The yielding evaluation criterion used as a basis for the interpretation of numerical model results, as it is applied to the assessment of geotechnical stability of

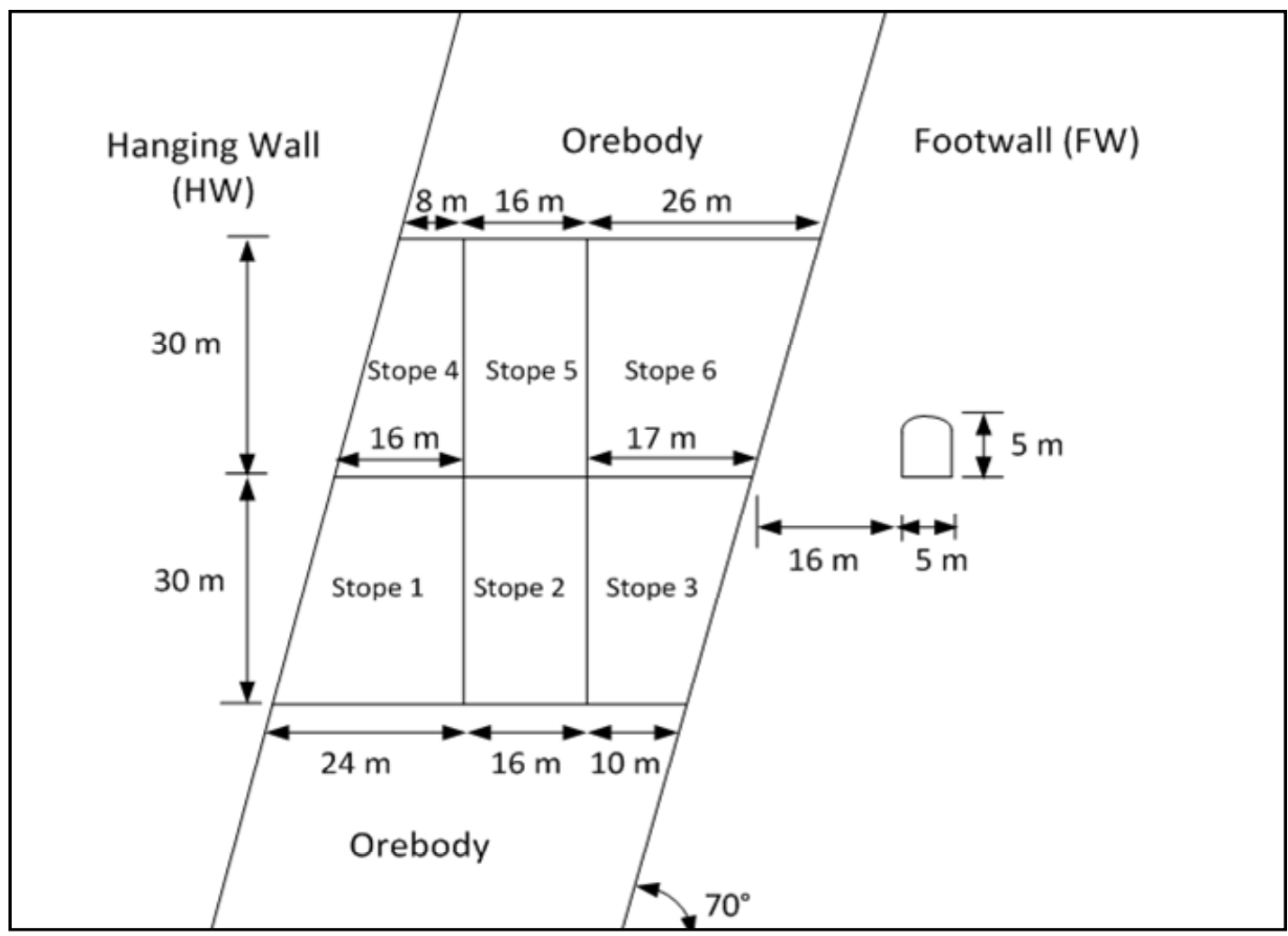

Fig. 1 Model geometry and its dimensions. 
Table 1 Model geo-mechanical properties [3].

\begin{tabular}{|c|c|c|c|}
\hline \multirow{2}{*}{ Rockmass property } & \multicolumn{3}{|c|}{ Domain } \\
\hline & HW & Orebody & FW \\
\hline Density $\left(\mathrm{kg} / \mathrm{m}^{3}\right)$ & 2,782 & 4,531 & 2,916 \\
\hline $\begin{array}{l}\text { UCS (unconfined compressive } \\
\text { strength), (MPa) }\end{array}$ & 90 & 90 & 172 \\
\hline Young’s modulus, $E$ (GPa) & 25 & 20 & 40 \\
\hline Poisson’s ratio, $\vartheta$ & 0.25 & 0.26 & 0.18 \\
\hline Cohesion, $C(\mathrm{MPa})$ & 4.8 & 10.2 & 14.13 \\
\hline Tensile strength, $\sigma_{t}(\mathrm{MPa})$ & 0.11 & 0.31 & 1.52 \\
\hline Friction angle, $\phi($ deg$)$ & 38 & 43 & 42.5 \\
\hline Dilation angle, $\Psi$ (deg) & 9 & 11 & 10.6 \\
\hline
\end{tabular}

Table 2 Backfill mechanical properties [3].

\begin{tabular}{lc}
\hline property & Backfill \\
\hline Density $\left(\mathrm{kg} / \mathrm{m}^{3}\right)$ & 2,000 \\
$\mathrm{UCS}(\mathrm{MPa})$ & 3 \\
Young's modulus, $E(\mathrm{GPa})$ & 0.1 \\
Poisson's ratio, $\vartheta$ & 0.3 \\
Cohesion, $C(\mathrm{MPa})$ & 1 \\
Tensile strength, $\sigma_{t}(\mathrm{MPa})$ & 0.01 \\
Friction angle, $\phi(\mathrm{deg})$ & 30 \\
Dilation angle, $\Psi(\mathrm{deg})$ & 0 \\
\hline
\end{tabular}

the modeled haulage drift with respect to two mining scenarios, is described below.

About extent of yield zones, yielding is the most common criterion used in numerical modelling when elastoplasticity is employed. The condition of yielding is reached when the stress state reaches the surface of the yield function, which is when the rock is loaded beyond its elastic limit. Thus, this criterion is used to estimate drift instability or unsatisfactory performance. In this investigation, the Mohr-Coulomb yield function is adopted and elastoplastic behaviour of the rockmass is used in Ref. [1]. Further, yielding will be considered a measure for drift unsatisfactory performance if it extends beyond a certain depth into the roof or sidewalls of the haulage drift. A rule of thumb is being used herein, whereby the resin grouted rebar can sustain 1-ton of axial load per 1-inch anchorage length of the bolt.

For the purpose of this study, yielding criterion is adopted based on Mohr-Coulomb. A minimum resin embedment length of $30 \mathrm{~cm}$ (12 in) in the drift back and on the sidewalls is taken for Grade 60, $19 \mathrm{~mm}$ diameter (3/4 inches) resin grouted rebar to reach the $134 \mathrm{KN}$ full capacity. Thus, the haulage drift performance is considered unsatisfactory when the extent of yield zones around haulage drift back and drift sidewalls exceeds $2.1 \mathrm{~m}$ and $1.5 \mathrm{~m}$, respectively.

Two different mining sequences have been simulated. The first approach (practiced on Garson Mine) is achieved by excavating the lower stopes (Stopes 1, 2 and 3) followed by excavating the upper stopes (Stopes 4, 5 and 6), respectively. The second mining scenario is done by excavating Stopes 1, 2, 4, 3, 5 and 6, respectively. Each stope is extracted and backfilled before the next mining sequence proceeds.

\section{Numerical Modeling}

This section is divided into two parts, the deterministic model and the stochastic analysis (random simulations). Numerical modelling is performed using Itasca's FLAC software [6]. The mean values for all rockmass parameters are used in the deterministic model. Both the mean and standard deviation of the stochastic parameters are used to perform random simulation.

\subsection{Deterministic Model}

The deterministic model is built using finite difference code software (FLAC) [6], to represent a typical section in the \#1 Shear-East zone orebody of Garson Mine, Vale, Sudbury, Ontario. Only the region around the haulage drift is discretized to be a dense grid (e.g. the model results are sensitive to the meshing size). Three different rock types representing HW, orebody MASU and FW are simulated. The haulage drift is driven in the footwall and its dimensions are $5 \mathrm{~m}$ by 5 $\mathrm{m}$ with slightly arch-shaped roof. The distance between the haulage drift and the orebody is $16 \mathrm{~m}$. Six stopes are extracted in two different mining sequences with delayed backfill. Numerical simulation has been performed to investigate the effect of two different mining sequences on the drift stability. 


\subsubsection{Extent of Yielding-Sequence 1}

In this scenario (practiced by Garson Mine), mining steps will be as follows: Stope 1, Stope 2, Stope 3, Stope 4, Stope 5 and Stope 6. Table 3 represents the development of the yield zone around the haulage drift due to the effect of mining extraction. Fig. 2 shows the progression of yielding after excavating Stope 3 and Stope 4, respectively (sequence 1 ).

\subsubsection{Extent of Yielding-Sequence 2}

The mining sequences with this scenario (proposed) are: Stope 1, Stope 2, Stope 4, Stope 3, Stope 5 and Stope 6. Table 4 gives the deterministic values of the yield zones around the haulage drift with respect to the proposed mining scenario. Fig. 3 depicts the progression of the yield zone (sequence 2) after excavating Stope 4 and Stope 3, respectively. Fig. 4 depicts the yielding progression with respect to two different mining sequences.

As shown in Figs. 2-4, the extent of yielding exceeds the threshold (1.5 m) after excavating Stope 2 (Step 2) for both mining sequences at the drift sidewalls. It can

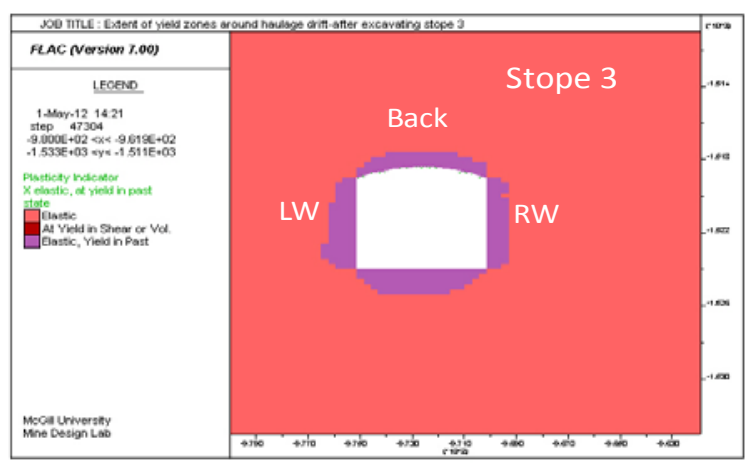

Fig. 2 Progression of yield zones with sequence 1.
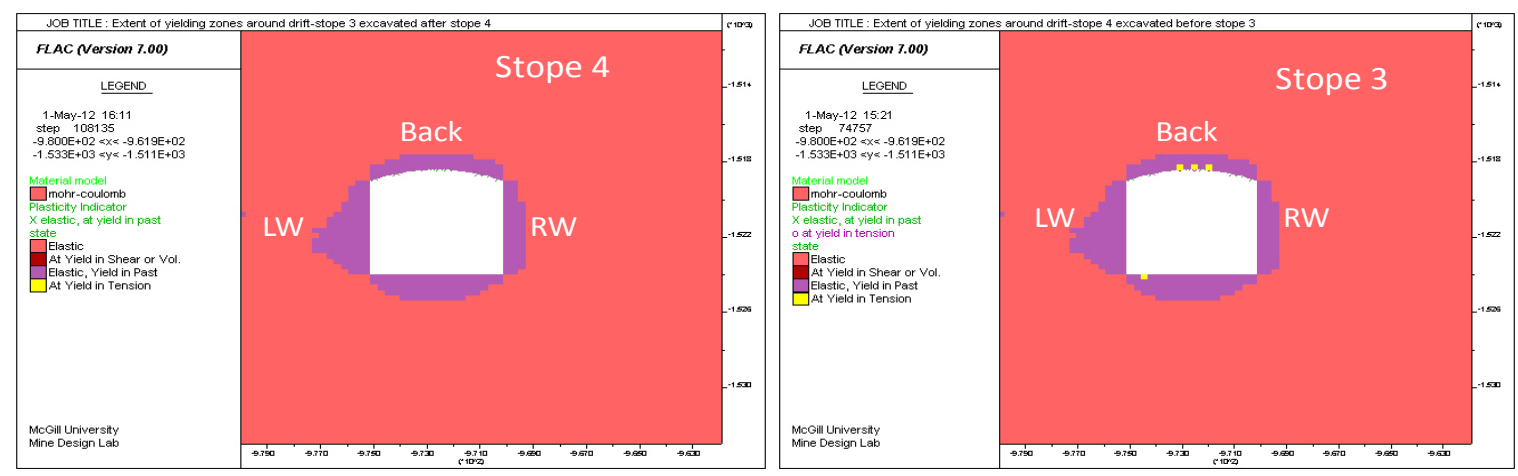

be seen that the extent of yielding, when extracting Stope 3 first (sequence 1), is almost twice that when excavating Stope 4 first (sequence 2) at the drift LW (left wall) at the same mining step. Also, it is seen that the length of yielding in the drift RW (right wall) is almost three times for sequence 1 , than that for sequence 2 at the same mining step (Step 3). The drift back will require enhanced support at a late stage (Step 6) for both mining scenarios. However, the probability of instability is unknown; thus, stochastic analyses are performed as in the next section.

Table 3 Extent of yield zones for mining sequence 1.

\begin{tabular}{llll}
\hline \multirow{2}{*}{ Mining step } & \multicolumn{3}{c}{ Extent of yield zones (m) } \\
\cline { 2 - 4 } & Roof & LW & RW \\
\hline 0 (Drift excavation) & 0.82 & 1.15 & 0.86 \\
1 (Stope 1 excavation) & 0.80 & 1.40 & 0.86 \\
2 (Stope 2 excavation) & 1.61 & 2.02 & 1.70 \\
3 (Stope 3 excavation) & 1.57 & 4.13 & 2.30 \\
4 (Stope 4 excavation) & 0.80 & 1.94 & 0.88 \\
5 (Stope 5 excavation) & 1.59 & 4.11 & 2.33 \\
6 (Stope 6 excavation) & 2.71 & 15.32 & 3.12 \\
\hline
\end{tabular}

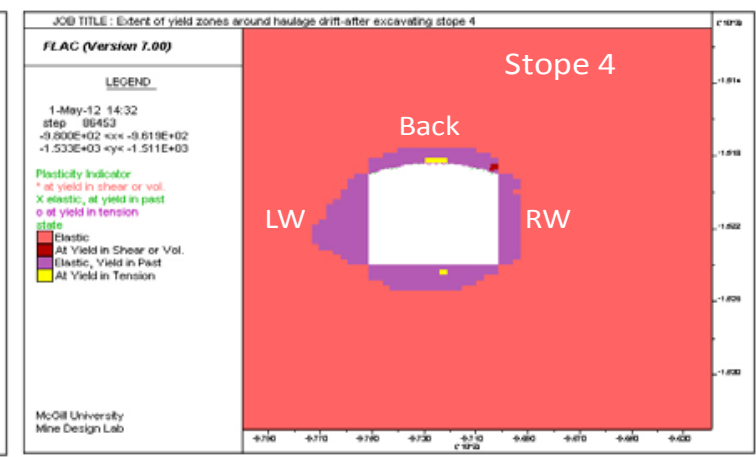

Fig. 3 Progression of yield zones with sequence 2. 


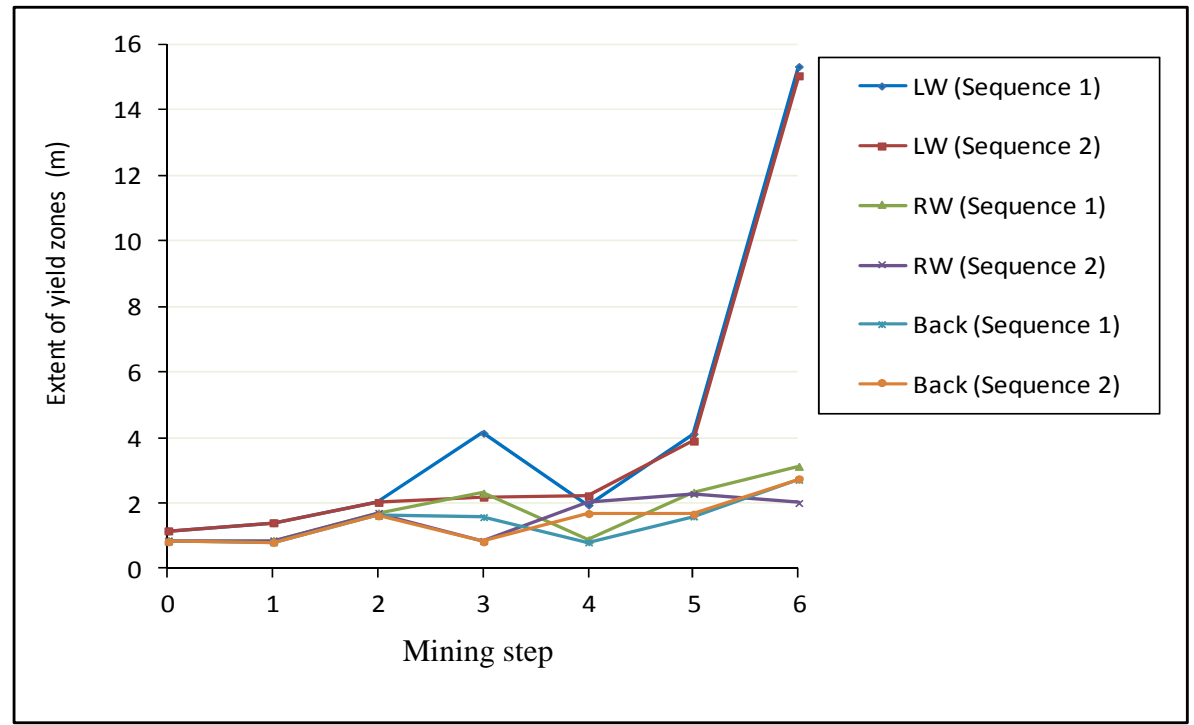

Fig. 4 Yield zone extension for two different mining sequences (deterministic analysis).

\subsection{Stochastic Analysis}

RMC technique is adopted to carry out the stochastic analysis and simulation. It includes varying the material properties spatially within the same region. The means and standard deviations from the FW rock sample test data are used to establish a normal distribution. That distribution is then interrogated to simulate random material property values for input into the stochastic analysis. The simulated material property values of the footwall were then assigned into the model using an inbuilt function in FLAC. One hundred runs are completed with each mining scenario (practiced and proposed) to analyze the performance of the haulage drift from the model outputs, based on the extent of yield zones and with respect to each mining scenario.

Based on the parametric study (sensitivity analyses) that has been conducted, the most influential model input parameters are young's modulus $(E)$, cohesion $(C)$, angle of internal friction ( $\phi)$, and horizontal-to-vertical stress ratio $(K)$. In this study, Young's modulus $(E)$, cohesion $(C)$ and friction angle $(\phi)$ are considered with Mohr-Coulomb yielding zones as shown in Table 5 .

\subsubsection{Extent of Yielding-Sequence 1}

The RMC technique combined with numerical analysis is used to evaluate drift instability based on the yielding progression. The average values for extent of yielding (after 100 runs) are given in Table 6 .

According to the rule of thumb (1-inch of anchorage length for each 1-ton of axial load), the minimum required anchorage length is $30 \mathrm{~cm}$ (12 inches) to achieve full bar capacity. Thus, the thresholds for yielding extension, whereas the supported drift stability remains unaffected, are $2.1 \mathrm{~m}$ and $1.5 \mathrm{~m}$ in the drift back and drift sidewalls, respectively.

Table 4 Extent of yield zones for mining sequence 2.

\begin{tabular}{llcl}
\hline \multirow{2}{*}{ Mining step } & \multicolumn{3}{c}{ Extent of yield zones (m) } \\
\cline { 2 - 4 } & Roof & LW & RW \\
\hline 0 (Drift excavation) & 0.82 & 1.15 & 0.86 \\
1 (Stope 1 excavation) & 0.80 & 1.40 & 0.86 \\
2 (Stope 2 excavation) & 1.61 & 2.02 & 1.70 \\
3 (Stope 4 excavation) & 0.82 & 2.18 & 0.84 \\
4 (Stope 3 excavation) & 1.68 & 2.22 & 2.02 \\
5 (Stope 5 excavation) & 1.66 & 3.89 & 2.28 \\
6 (Stope 6 excavation) & 2.74 & 15.04 & 2.0 \\
\hline
\end{tabular}

Table 5 Material properties for footwall rock.

\begin{tabular}{llll}
\hline \multirow{2}{*}{ Rockmass properties } & \multicolumn{3}{c}{ Material parameters } \\
\cline { 2 - 4 } & Mean $(\mu) \begin{array}{l}\text { STDEV } \\
(\sigma)\end{array}$ & $\operatorname{COV}\left(\frac{\sigma}{\mu}\right)$ \\
\hline Young's modulus $(E),(\mathrm{GPa})$ & 40 & 8 & 0.20 \\
Cohesion $(C),(\mathrm{MPa})$ & 14.13 & 2.83 & 0.20 \\
Friction angle $(\phi),($ deg.) & 42.5 & 8.5 & 0.20 \\
\hline
\end{tabular}


Table 6 Average extent of yield zones for mining sequence 1 (stochastic analysis).

\begin{tabular}{llll}
\hline \multirow{2}{*}{ Mining step } & \multicolumn{3}{l}{ Average extent of yield zones (m) } \\
\cline { 2 - 4 } & Roof & LW & RW \\
\hline 0 (Drift excavation) & 1.62 & 1.69 & 1.69 \\
1 (Stope 1 excavation) & 1.61 & 2.12 & 1.75 \\
2 (Stope 2 excavation) & 1.62 & 2.21 & 1.76 \\
3 (Stope 3 excavation) & 1.65 & 2.51 & 1.84 \\
4 (Stope 4 excavation) & 1.67 & 3.76 & 2.10 \\
5 (Stope 5 excavation) & 1.70 & 3.81 & 2.17 \\
6 (Stope 6 excavation) & 2.67 & 15.79 & 2.35 \\
\hline
\end{tabular}

Based on the stochastic results for mining sequence 1 , in comparison to the threshold for yielding extension into the rockmass, enhanced support in the back is not required until after excavating Stope 5 (or before mining Stope 6). However, with sequence 1, stochastic results for the drift sidewalls indicate that enhanced wall support is required immediately at the time of drift excavation.

\subsubsection{Extent of Yielding-Sequence 2}

According to this proposed mining sequence, Stope 4 is excavated before Stope 3 . Table 7 gives the stochastic analysis after one-hundred simulations. Based on the results for mining sequence 2 (presented in Table 7) enhanced support in the back is not required until after excavating Stope 5 (or before mining Stope 6), However, enhanced support of the sidewalls is required immediately upon excavation of haulage drift, according to the stochastic results in Table 7. A comparison of stochastic analyses between these two mining scenarios is shown in Fig. 5.

In Fig. 5, the timeline (or mining sequence steps) corresponding to a requirement of secondary support installation for the drift back and walls is identical, based on the extent of yield reaching beyond the primary support capacity length. In both sequences, secondary support of the sidewalls is required at the time of drift excavation (mining Stope 0) and secondary support of the back is required just prior to excavating the last stope (mining Stope 6).

Therefore, although the mining sequences were different, the step in the sequence where the secondary support becomes a requirement does not change. The timing of the secondary support requirement is irrespective of the stoping sequence, but rather seems to be dependent on the amount of stopes mined out.

Although the timing of the secondary support requirement remains unchanged, the progression of the yield zone into the rockmass varies significantly,

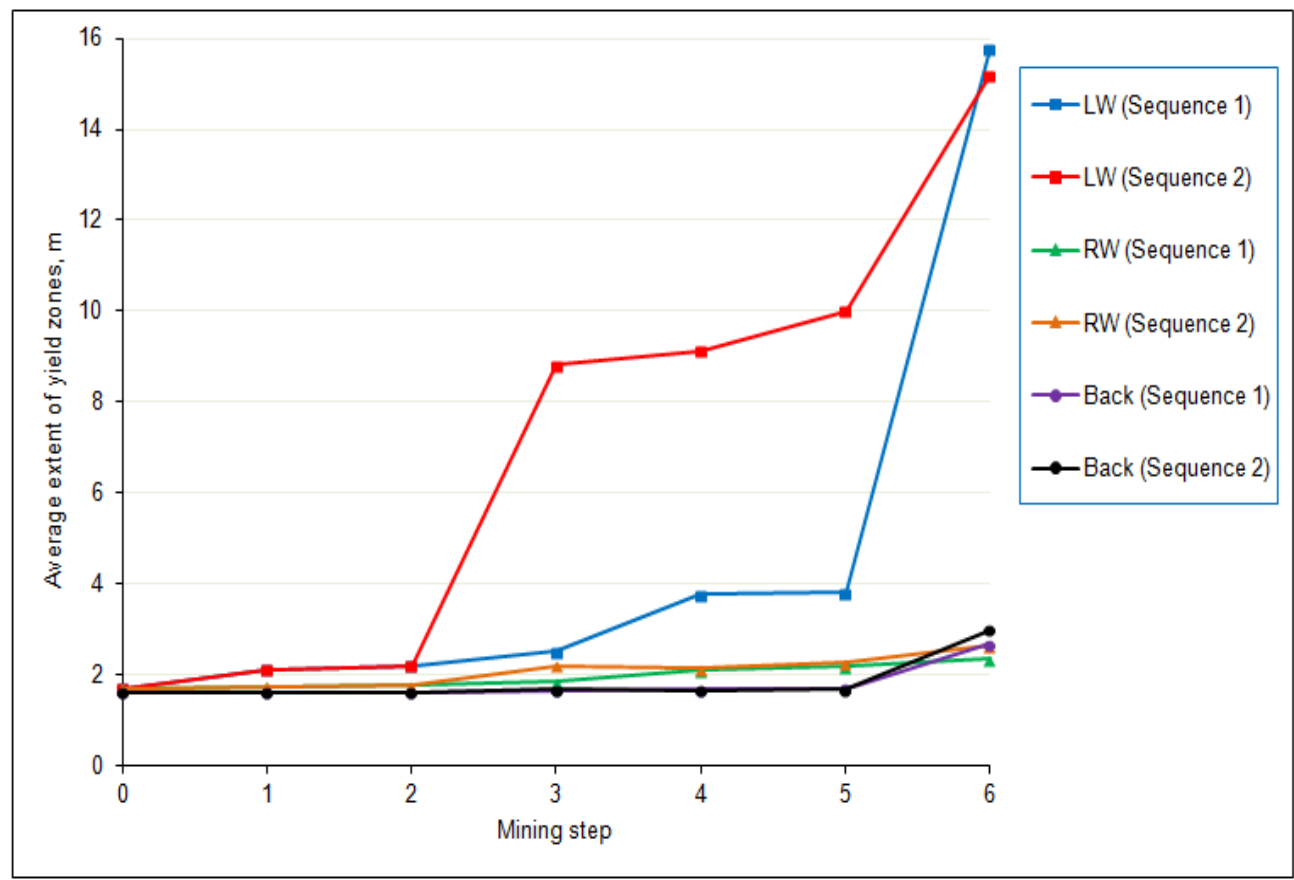

Fig. 5 Average length of yield zones extension vs. two different mining scenarios (stochastic analysis). 
Table 7 Average extent of yield zones for mining sequence 2 (stochastic analysis).

\begin{tabular}{llll}
\hline \multirow{2}{*}{\multicolumn{1}{c}{ Mining step }} & \multicolumn{3}{c}{ Average extent of yield zones (m) } \\
\cline { 2 - 4 } & Roof & LW & RW \\
\hline 0 (Drift excavation) & 1.62 & 1.69 & 1.69 \\
1 (Stope 1 excavation) & 1.61 & 2.12 & 1.75 \\
2 (Stope 2 excavation) & 1.62 & 2.21 & 1.76 \\
3 (Stope 4 excavation) & 1.67 & 8.82 & 2.20 \\
4 (Stope 3 excavation) & 1.66 & 9.12 & 2.14 \\
5 (Stope 5 excavation) & 1.67 & 10.0 & 2.26 \\
6 (Stope 6 excavation) & 3.0 & 15.20 & 2.64 \\
\hline
\end{tabular}

depending on the mining sequence. The average values of yielding extension, according to Tables 6 and 7 around the left wall of the drift with sequence 2 are $8.82 \mathrm{~m}$ and $9.12 \mathrm{~m}$ after mining Step 3 and Step 4, respectively. Whilst the average yielding values with sequence 1 are $2.51 \mathrm{~m}$ and $3.76 \mathrm{~m}$ after mining Step 3 (Stope 3) and Step 4 (Stope 4), respectively. In mining sequence 1 , the extent of the yield zone does not exceed $3 \mathrm{~m}$ until the final mining steps (e.g., Stope 4 to Stope 6). However, in mining sequence 2, the extent of the yield zone jumps up to almost $9 \mathrm{~m}$ in the left wall earlier in the sequence, at mining Stope 3. At almost 3.5 times greater the extent of yield in the left wall, as compared to sequence 1 at the same mining Stope 3, additional support measures at an earlier stage of mining would need to be considered to maintain overall drift stability.

\subsection{Probability of Unsatisfactory Performance}

To estimate the probability of instability for the haulage drift, lognormal distributions of 100 simulations for yield zone extension into the drift RW after mining Stope 3 and Stope 4 have been plotted for each mining sequence, as shown in Figs. 6a-6d. Probability of instability is estimated for drift back and sidewalls, in relation to the primary support anchorage length.

It can be seen from these lognormal distribution that, as mining proceeds, the probability of instability increases (i.e., the threshold or "cut-off" is laterally shifted to the left side). The difference between sequence 1 and sequence 2 , in terms of PDF (probability density function) lognormal distribution, is that with sequence 2 , the probability of instability increases earlier in the mining steps. Specifically, after mining Stope 3 with sequence 2, the probability of instability in the drift RW (right wall) becomes $89.25 \%$ comparing with $54.38 \%$ (with sequence 1 ).

Probability of instability (P(i)) of drift, is estimated from lognormal distributions at cut-off $2.1 \mathrm{~m}$ and $1.5 \mathrm{~m}$ of yielding on the drift back and driftwalls, respectively. The areas under these curves (e.g., which represent the P(i)) are obtained from Z-tables (standardized normal variate) after transforming lognormal to standardized normal variate. The probability of unsatisfactory performance $(\mathrm{P}(\mathrm{i})$ ) of haulage drift with respect to mining sequences is estimated as shown in Tables 8 and 9.

Evaluation of the data in Tables 8 and 9 demonstrate minimal variation in the probability of instability between the two different mining sequences (i.e., probability value can not show more than 100\%). Furthermore, evaluation on the extent of yielding between the two sequences results in values exceeding the primary support threshold. However, mining sequence 2 demonstrates yielding lengths 2 to 3.5 times greater at an earlier stage of mining, as compared to mining sequence 1 .

The suggested ratings of probability and rankings are tabulated in Table 10 [7]. Probability of instability for the stochastic analyses are plotted in Fig. 7.

In Fig. 7, it is evident that the drift left wall falls into the "certain" range for probablity of instability early in the mining cycle, regardless of the sequence employed. Furthermore, the back stability remains in the "unlikley" range for almost the entire mining cycle, also regardless of the sequence employed. Probability of instability along the right wall (RW), however, does vary depending on the mining sequence and step. It can be seen from Fig. 7 that the probability of instability for the drift RW with sequence 2 after mining Stope 4 and Stope 3 becomes certain (i.e., $P(i)=91.62 \%$ and $89.25 \%$, 

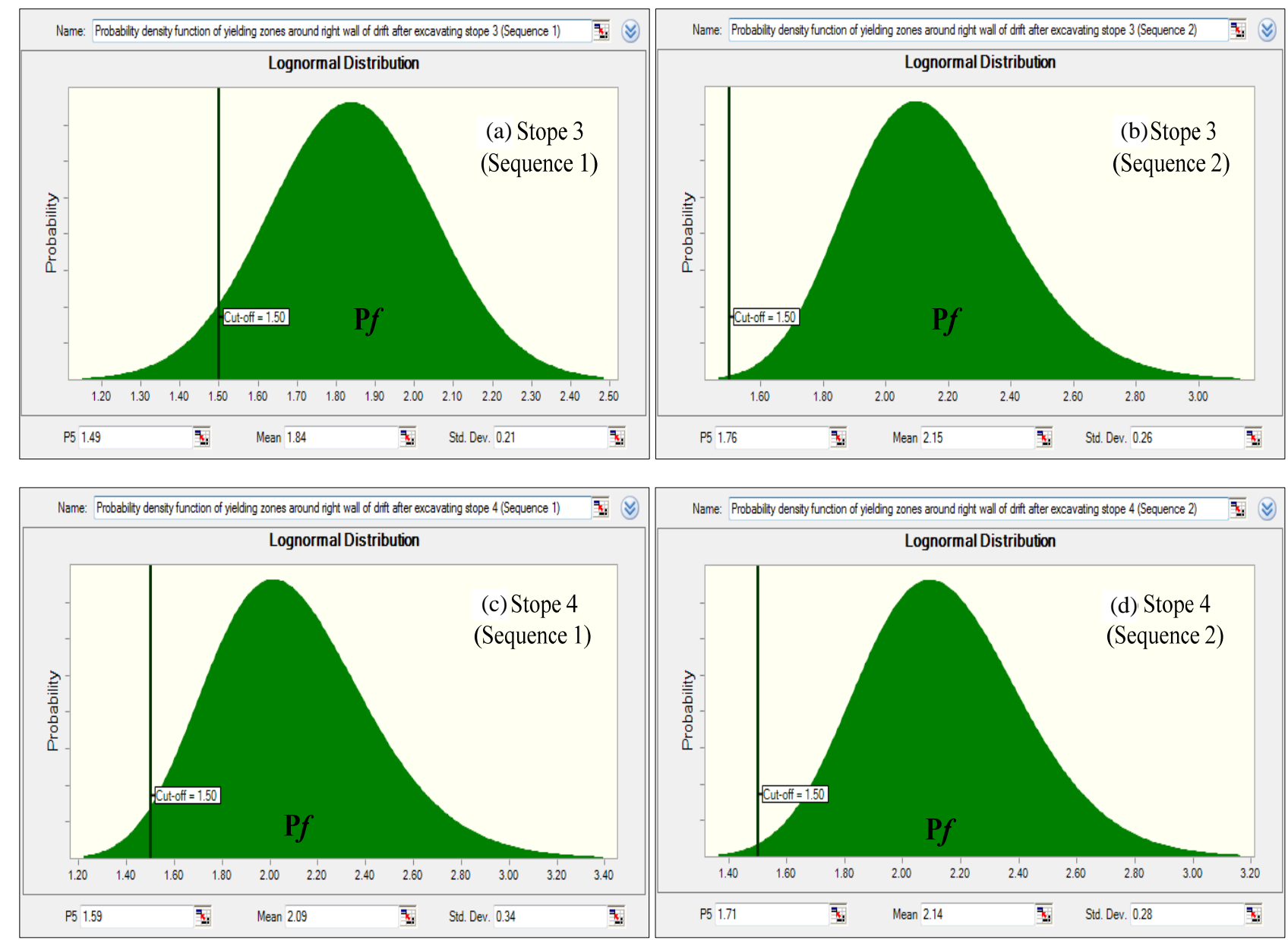

Fig. 6 Probability density function for yielding extension in right wall for Stope 3 and Stope 4 with two mining scenarios.

Table 8 Probability of instability of haulage drift with respect to mining sequence 1 .

\begin{tabular}{lrcl}
\hline \multirow{2}{*}{ Mining step } & \multicolumn{3}{c}{$\mathrm{P}(\mathrm{i})(\%)$} \\
\cline { 2 - 4 } & \multicolumn{1}{c}{ Roof } & \multicolumn{1}{c}{ LW } & RW \\
\hline 0 (Drift excavation) & 3.67 & 28.1 & 27.76 \\
1 (Stope 1 excavation) & 3.67 & 82.12 & 38.21 \\
2 (Stope 2 excavation) & 3.44 & 88.1 & 40.13 \\
3 (Stope 3 excavation) & 3.59 & 95.82 & 54.38 \\
4 (Stope 4 excavation) & 4.75 & 100 & 79.67 \\
5 (Stope 5 excavation) & 3.92 & 100 & 82.12 \\
6 (Stope 6 excavation) & 84.85 & 100 & 94.52 \\
\hline
\end{tabular}

Table 9 Probability of instability of haulage drift with respect to mining sequence 2 .

\begin{tabular}{llll}
\hline \multirow{2}{*}{ Mining step } & \multicolumn{3}{c}{$\mathrm{P}(\mathrm{i})(\%)$} \\
\cline { 2 - 4 } & Roof & $\mathrm{LW}$ & $\mathrm{RW}$ \\
\hline 0 (Drift excavation) & 3.67 & 28.1 & 27.76 \\
1 (Stope 1 excavation) & 3.67 & 82.12 & 38.21 \\
2 (Stope 2 excavation) & 3.44 & 88.1 & 40.13 \\
3 (Stope 4 excavation) & 3.75 & 100 & 89.25 \\
4 (Stope 3 excavation) & 4.36 & 100 & 91.62 \\
5 (Stope 5 excavation) & 4.09 & 99.94 & 92.07 \\
6 (Stope 6 excavation) & 90.82 & 100 & 97.56 \\
\hline
\end{tabular}

Table 10 Suggested ratings of likelihood and ranking of $P(i)$ [7].

\begin{tabular}{llll}
\hline Rating & Likelihood ranking & & Probability of occurrence \\
\hline 1 & Rare & $<5 \%$ & May occur in exceptional circumstances \\
2 & Unlikely & $5 \%-20 \%$ & Could occur at sometime \\
3 & Possible & $20 \%-60 \%$ & Might occur at sometime \\
4 & Likely & $60 \%-85 \%$ & Will probably occur in most circumstances \\
5 & Certain & $>85 \%$ & Expected to occur in most circumstances \\
\hline
\end{tabular}




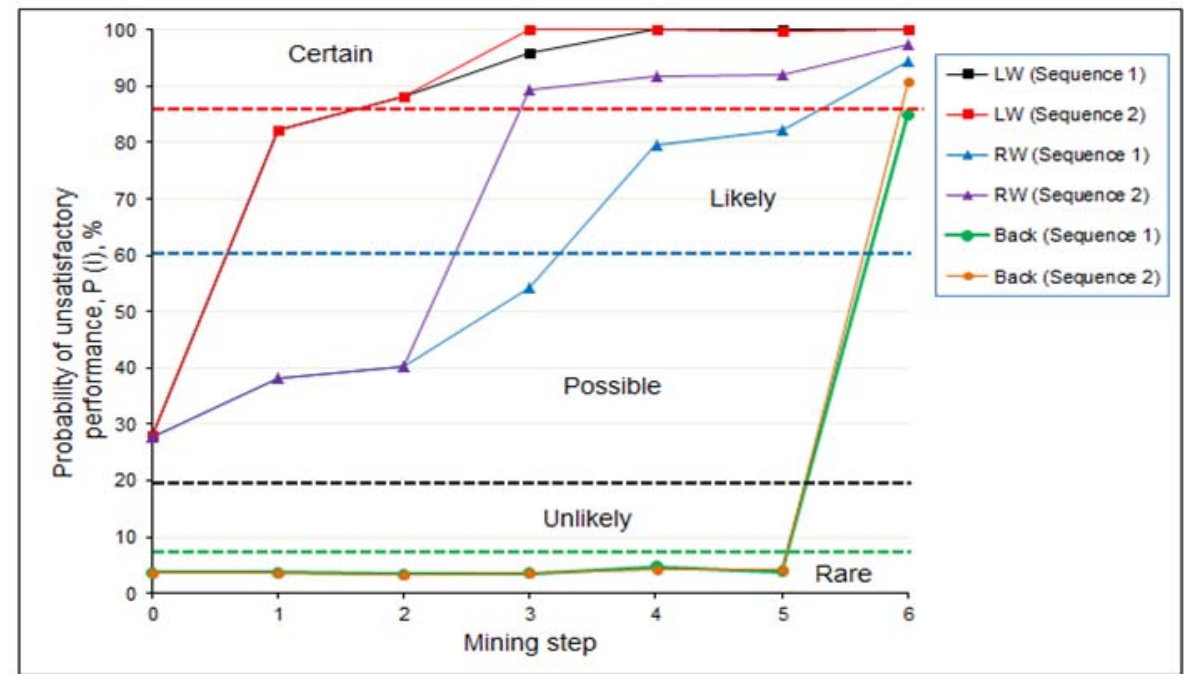

Fig. 7 Probability of instability (P(i)) for haulage drift due to yielding condition.

respectively). But, with mining sequence 1 , it becomes possible (i.e., $P(i)=54.38 \%$ ) after mining Stope 3 and becomes likely (i.e., $P(i)=79.67 \%$ ) after mining Stope 4. Therefore, mining sequence 1 offers a lower risk (or probability of instability) to the drift, up until mining Step 6.

\section{Conclusions}

This paper presents the results of a stepwise methodology to evaluate probability of haulage drift stability due to stress interaction between the haulage drift and nearby mining activity. The methodology used to evaluate probability of stability from numerical stress modelling employed RMC in conjunction with finite difference modelling software FLAC.

Mohr-Coulomb yielding criterion is adopted. Two mining sequences have been simulated and compared. These are: Sequence 1 (Stopes 1, 2, 3, 4, 5 and 6) and Sequence 2 (Stopes 1, 2, 4, 3, 5 and 6). The stochastic analysis shows that sequence 2 gives higher values of yielding progression in the drift RW after excavating Stopes 1, 2, 4 and 3 and the $P(i)$, is greater than $85 \%$. The corresponding $P(i)$ for sequence 1 after the extraction of Stopes 1, 2, 3 and 4 is less than $80 \%$, hence a better option.

It is noteworthy that model failure criterion must be calibrated based on underground measurements.
Currently, a 3-dimensional mine wide model which represents the real geometry of Garson Mine and includes the dyke, shear zones and all other geological units is calibrated based on in-situ stress measurements and validated with underground instruments such as deformation monitoring (MPBX) [8].

\section{Acknowledgments}

This work is financially supported by a research grant from the Natural Sciences and Engineering Research Council of Canada in partnership with Vale ltd.. The authors are grateful for their support.

\section{References}

[1] Y. Zhang, H.S. Mitri, Elastoplastic stability analysis of mine haulage drift in the vicinity of mined stopes, International Journal of Rock Mechanics and Mining Sciences 45 (2008) 574-593.

[2] Vale Inco Limited, Garson Deep Pre-Feasibility Study/FEL 2, Geotechnical report, Feb. 2009.

[3] Golder Associate and MIRARCO, Geotechnical Study_Garson Mine, Project report, Oct. 31, 2008.

[4] Y. Kwangho, P. Yeonjun, L.S. Jun, Risk analysis for determination of a tunnel support pattern, Tunnelling and Underground Space Technology 20 (2005) 479-486.

[5] G.S. Kalamaras, A case method approach for interactive risk analysis of tunnel design-for-constructability concept, Ph.D. Thesis, The Pennsylvania State University, 1996, p. 217.

[6] ITASCA Consulting Group, Inc., FLAC-Fast 
Lagrangian Analysis of Continua, Ver. 6, Itasca Consulting Group, Minneapolis, Minnesota, USA, 2008.

[7] W. Abdellah, H.S. Mitri, D. Thibodeau, L. Moreau-Verlaan, Stochastic evaluation of haulage drift unsatisfactory performance using random Monte-Carlo simulation, Int. J. Mining and Mineral Engineering 4 (1)
(2012) 63-87.

[8] W. Abdellah, D. Raju, H.S. Mitri, D. Thibodeau, Stability of underground mine development intersections during the life of a mine plan, International Journal of Rock Mechanics and Mining Sciences (IJRMMS), 2013. (in print). 